\title{
Association of single nucleotide polymorphisms in $I L 8$ and $I L 13$ with sunitinib-induced toxicity in patients with metastatic renal cell carcinoma
}

\author{
Meta H. M. Diekstra ${ }^{1,2} \cdot$ Xiaoyan Liu ${ }^{1,2,3}$ - Jesse J. Swen ${ }^{1,2}$ - Epie Boven ${ }^{2,4}$. \\ Daniel Castellano $^{5,6}$ • Hans Gelderblom ${ }^{2,7}$ • Ron H. J. Mathijssen ${ }^{2,8}$. \\ Cristina Rodríguez-Antona ${ }^{9,10}$ • Jesus García-Donas ${ }^{6,11}$ • Brian I. Rini ${ }^{12}$. \\ Henk-Jan Guchelaar ${ }^{1,2}$
}

Received: 22 July 2015 / Accepted: 31 August 2015 /Published online: 21 September 2015

(C) The Author(s) 2015. This article is published with open access at Springerlink.com

\begin{abstract}
Purpose Earlier, the association of single nucleotide polymorphisms (SNPs) with toxicity and efficacy of sunitinib has been explored in patients with metastatic renal cell carcinoma (mRCC). Recently, additional SNPs have been suggested as potential biomarkers. We investigated these novel SNPs for association with sunitinib treatment outcome in $\mathrm{mRCC}$ patients. Methods In this exploratory study, we selected SNPs in genes CYP3A4, NR1I2, POR, IL8, IL13, IL4-R, HIF1A and MET that might possibly be associated with sunitinib treatment outcome. Each SNP was tested for association with progressionfree survival (PFS) and overall survival (OS) by Coxregression analysis and for clinical response and toxicity using logistic regression.
\end{abstract}

Meta H. M. Diekstra and Xiaoyan Liu contributed equally to this work.

Electronic supplementary material The online version of this article (doi:10.1007/s00228-015-1935-7) contains supplementary material, which is available to authorized users.

Jesse J. Swen

j.j.swen@lumc.nl

1 Department of Clinical Pharmacy and Toxicology, Leiden University Medical Center, Albinusdreef 2, Leiden 2333ZA, Netherlands

2 Dutch SUTOX consortium, Leiden, Netherlands

3 Institute of Clinical Pharmacology, Qilu Hospital of Shandong University, Jinan, China

4 Department of Medical Oncology, VU University Medical Center, Amsterdam, Netherlands

5 Oncology Department, Hospital Universitario 12 de Octubre, Madrid, Spain

6 Spanish Oncology Genitourinary Group (SOGUG), Madrid, Spain
Results We included 374 patients for toxicity analyses, of which 38 patients with non-clear cell renal cell cancer were excluded from efficacy analyses. The risk for hypertension was increased in the presence of the $\mathrm{T}$ allele in IL8 $\mathrm{rs} 1126647(\mathrm{OR}=1.69,95 \% \mathrm{CI}=1.07-2.67, P=$ 0.024). The $\mathrm{T}$ allele in IL13 rs 1800925 was associated with an increase in the risk of leukopenia $(\mathrm{OR}=6.76$, $95 \% \mathrm{CI}=1.35-33.9, P=0.020)$ and increased prevalence of any toxicity $>$ grade $2(\mathrm{OR}=1.75,95 \% \mathrm{CI}=1.06-2.88$, $P=0.028)$. No significant associations were found with PFS, OS or clinical response.

Conclusions We show that polymorphisms in IL8 rs1126647 and IL13 rs1800925 are associated with sunitinib-induced toxicities. Validation in an independent cohort is required.

7 Department of Medical Oncology, Leiden University Medical Center, Leiden, Netherlands

8 Department of Medical Oncology, Erasmus MC Cancer Institute, Rotterdam, Netherlands

9 Hereditary Endocrine Cancer Group, Spanish National Cancer Research Centre (CNIO), Madrid, Spain

10 ISCIII Center for Biomedical Research on Rare Diseases (CIBERER), Madrid, Spain

11 Oncology Unit, Clara Campal Comprehensive Cancer Center, Madrid, Spain

12 Department of Solid Tumor Oncology, Cleveland Clinic Taussig Cancer Institute (CCF), Cleveland, OH, USA 
Keywords Tyrosine kinase inhibitor $\cdot$ Sunitinib $\cdot$ Metastatic renal cell carcinoma $\cdot$ Single nucleotide polymorphism .

Toxicity $\cdot$ Progression-free survival

\section{Introduction}

Several targeted therapies have been approved for the treatment of metastatic renal cell carcinoma (mRCC). Of these, the tyrosine kinase inhibitor (TKI) sunitinib is widely used as first-line treatment option [1-4]. The response to sunitinib varies largely among patients. Only $35 \%$ of mRCC patients benefit from sunitinib, and about $30 \%$ of patients need dose reductions due to adverse events of which grades vary among patients $[1,5,6]$. To optimize treatment efficacy and to minimize the risk of adverse events of higher grades, it would be helpful to predict the individual treatment outcome at the initiation of therapy. Unfortunately, no biomarkers are yet available to fulfil this need.

Several studies used a candidate gene approach to select single nucleotide polymorphisms (SNPs) in genes involved in the pharmacokinetics and pharmacodynamics of sunitinib. SNPs and haplotypes in CYP1A1, CYP3A5, ABCB1, ABCG2, NR113, VEGFA, NOS3 (=eNOS), FLT1 (=VEGFR1), KDR (=VEGFR2), FLT-4 (=VEGFR3) and FLT3 have been described to have an association with either toxicity or efficacy of sunitinib $(P<0.05)$ in $\mathrm{mRCC}$ patients [5-11]. The associations of $C Y P 3 A 5$ and $A B C B 1$ with dose reductions and efficacy, respectively, have been confirmed recently [12]. Not all clinical outcomes can be explained by these potential biomarkers, which make identification of other markers possibly associated with clinical outcome an attractive prospect.

Novel SNPs in CYP3A4, NR1I2, POR, IL8, IL4-R, IL13, HIF1A and MET have been reported in patients with RCC, either prognostic or associated with treatment outcome, and might play a role in sunitinib treatment outcome (Table 1) [13-20]. In some studies on these novel SNPs, the TKI pazopanib was given to patients with mRCC. Sunitinib and pazopanib have similar efficacy and both are used as first-line treatment options [2]. Further, both drugs have similarities in their metabolic pathways and affected targets, because of which SNPs associated with pazopanib outcome might also be meaningful for the sunitinib treatment outcome, i.e. toxicity or efficacy [21]. The T allele of SNP rs35599367 in CYP3A4 $\left(C Y P 3 A 4^{*} 22\right)$ was associated with decreased clearance of sunitinib [13-15]. The T allele of SNP rs3814055 in NR1I2 was associated with a reduction in response to pazopanib and inferior progression-free survival (PFS) from sunitinib and pazopanib in univariate analysis $[6,16]$. The TT genotype of SNP rs1057858 in the P450 oxidoreductase gene $\left(P O R^{*} 28\right)$ was associated with higher CYP3A activity [17, 18]. Variant alleles of rs4073 and rs 1126647 in $I L 8$ were associated with an inferior PFS on pazopanib treatment [16]. SNPs rs 1800925 and rs20541 in $I L 13$ and rs180510 in IL4-R are likely to influence tumour immune response and carcinogenesis [19]. The AG genotype of rs 11549467 in HIF1A compared to wild-type GG was associated with a decreased PFS and a reduced response rate on pazopanib treatment [16]. The Aallele of SNP rs11762213 in MET was associated with an increased risk of recurrence or death in RCC patients [20].

Table 1 Polymorphisms in candidate genes in the current study. Genetic polymorphisms were included if in previous exploratory studies associations were reported with a $P$ value $<0.05$

\begin{tabular}{|c|c|c|c|}
\hline Gene & SNP & Reported results & References \\
\hline CYP $3 A 4$ & rs $35599367 \mathrm{C}>\mathrm{T}$ & $\begin{array}{l}\text { CYP } 3 A 4 * 22 \text { is associated with decreased CYP3A4 } \\
\text { expression and decreased clearance of sunitinib. }\end{array}$ & $\begin{array}{l}\text { Elens et al. [13, 14] } \\
\text { Diekstra et al. [15] }\end{array}$ \\
\hline NRII2 & $\mathrm{rs} 3814055 \mathrm{C}>\mathrm{T}$ & $\begin{array}{l}\text { T allele is associated with reduction of response } \\
\text { to pazopanib and inferior PFS on sunitinib and pazopanib. }\end{array}$ & $\begin{array}{l}\text { van der Veldt et al. }[6 \\
\text { Xu et al. [16] }\end{array}$ \\
\hline$P O R^{*} 28$ & $\mathrm{rs} 1057868 \mathrm{C}>\mathrm{T}$ & POR $* 28$ is associated with higher in vivo CYP3A activity. & $\begin{array}{l}\text { de Jonge et al. [17] } \\
\text { Oneda et al. [18] }\end{array}$ \\
\hline \multirow[t]{3}{*}{ IL8 } & rs $4073 \mathrm{~T}>\mathrm{A}$ & AA shows inferior PFS of pazopanib compared to wild-type TT. & $\mathrm{Xu}$ et al. [16] \\
\hline & rs1126647A $>\mathrm{T}$ & TT shows inferior PFS of pazopanib compared to wild-type AA. & Xu et al. [16] \\
\hline & $\begin{array}{l}\text { Correlated SNPs rs } 4073 \mathrm{~T}>\mathrm{A} \text { and } \\
\quad \text { rs } 1126647 \mathrm{~A}>\mathrm{T}\end{array}$ & $\begin{array}{l}\text { Inferior PFS for variant genotypes }(\mathrm{r} 4073 \mathrm{AA}+\mathrm{rs} 1126647 \mathrm{TT}) \\
\text { compared to wild types }(\mathrm{rs} 4073 \mathrm{TT}+\mathrm{rs} 1126647 \mathrm{AA})\end{array}$ & $\mathrm{Xu}$ et al. [16] \\
\hline HIF $1 A$ & $\operatorname{rs} 11549467 \mathrm{G}>\mathrm{A}$ & $\begin{array}{l}\text { AG genotype is associated with inferior PFS and reduced } \\
\text { response rate of pazopanib compared to wild-type GG. }\end{array}$ & $\mathrm{Xu}$ et al. [16] \\
\hline IL4- $R$ & $\mathrm{rs} 1805010 \mathrm{~T}>\mathrm{C}$ & $\begin{array}{l}\mathrm{CT} / \mathrm{TT} \text { genotype is associated with decreased risk of RCC } \\
\text { compared to CC genotype. }\end{array}$ & Chu et al. [19] \\
\hline IL13 & $\begin{array}{l}\mathrm{rs} 1800925 \mathrm{C}>\mathrm{T} \\
\mathrm{rs} 20541 \mathrm{C}>\mathrm{T}\end{array}$ & TT genotype is associated with decreased risk of RCC. & Chu et al. [19] \\
\hline MET & rs $11762213 \mathrm{G}>\mathrm{A}$ & A-allele is associated with an increased risk of recurrence or death. & Schutz et al. [20] \\
\hline
\end{tabular}

SNP single nucleotide polymorphism, $P F S$ progression-free survival, $O S$ overall survival 
In this exploratory study, we evaluated the polymorphisms in the above-mentioned genes for possible associations with toxicity or efficacy of sunitinib in a large cohort of $\mathrm{mRCC}$ patients.

\section{Methods}

\section{Study population}

Patient data were collected from three exploratory studies (SUTOX, SOGUG and CCF) between the years 2004 and 2010 (Supplementary document 1) [12]. SUTOX samples were anonymized by a third party, according to the instructions stated in the Codes for Proper Use and Proper Conduct in the Self-Regulatory Codes of Conduct (www.federa.org). The study was conducted in accordance with the Declaration of Helsinki and approved by the medical ethics review board of all participating groups. Patients provided their written informed consent for participation [12].

\section{Study endpoints}

PFS, defined as the time in months between the first day of sunitinib treatment and the date of progressive disease (PD) according to Response Evaluation Criteria in Solid Tumours (RECIST) v.1.0 or v1.1, was used as the primary endpoint to assess efficacy. Another endpoint was overall survival (OS), which was measured from the first day of sunitinib treatment until death or time of last follow-up.

We classified objective clinical response into three categories: (i) partial and complete response, (ii) stable disease and (iii) progressive disease (according to RECIST).

Specific sunitinib-related adverse events, i.e. thrombocytopenia, leukopenia, mucosal inflammation, hand-foot syndrome, hypertension and any toxicity $>$ grade 2 , were collected for this study (Supplementary document 1) [12].

\section{Statistical analysis}

For univariate analysis, a log-rank test was used for the association of each SNP with PFS and OS, and a chisquare test for clinical response and toxicity. SNPs with a $P$ value $<0.1$ were included in the multivariate model. Based on previous results, we included well-established covariates age, gender and Heng prognostic risk group in the multivariate model for correction of PFS and OS [22]. In addition, the CGT haplotype of $A B C B 1$ was also used as covariate in multivariate Cox model because of the previously confirmed significant association with PFS [6, 12]. For multivariate analysis of clinical response, we also included age, gender and Heng prognostic risk group as covariates. For multivariate analysis on toxicity endpoints, no biomarker was widely validated, so we corrected for age and gender. Because this association study used data from three study groups (SUTOX, SOGUG and CCF), study group was also tested as a covariate for all endpoints. It was not needed to correct for previous treatment in efficacy analyses, because this was already justified by using study group as a covariate.

Reported results from the multivariate analysis with a $P$ value $<0.05$ were considered clinically significant. All tests were two-sided and carried out by SPSS Statistical Package for Windows (version 20.0 Armonk, NY: IBM Corp).

\section{Results}

\section{Patient characteristics}

A total of 374 patients with $\mathrm{mRCC}$ treated with sunitinib were included for association analyses on toxicity endpoints. For efficacy analyses, only clear cell subtypes $(N=336)$ were included (Fig. 1). Patient characteristics are presented in Table 2. Median age of patients was 61 years, and most were men of Caucasian ethnicity. The majority of patients had undergone nephrectomy. For the clear cell subjects, the good or intermediate Heng prognostic risk group consisted of $73 \%$ of the patients. Forty-five percent $(N=143)$ of patients showed a partial response (PR) or complete response (CR) to sunitinib.

95.7 to $99.5 \%$ of patients had no toxicities at baseline. Within four cycles of sunitinib treatment, any grade of thrombocytopenia was observed in $61 \%$ of patients, mucosal inflammation in $59 \%$, leukopenia in $49 \%$, hand-foot syndrome in $41 \%$ and hypertension in $38 \%$. Twenty-six percent of patients developed any toxicity $>$ grade 2 (Supplementary Table S1).

For clear cell subtypes, median follow-up times for PFS and OS analysis were 43 and 49 months, respectively. Median PFS and OS of patients were 16 and 26 months, respectively.

\section{Genotyping}

IL8 rs4073 was excluded from statistical analysis because the call rate was less than $95 \%$. The SNP genotype call rate for the remaining SNPs ranged from 97.6 to $99.7 \%$. All SNPs were in Hardy-Weinberg equilibrium (HWE) $\left(P>0.05\right.$ and $\chi^{2}$ $<3.84$ ). The allele frequencies of genotyped polymorphisms were similar as reported in the National Center for Biotechnology Information (NCBI) SNP database [23]. Only three patients with the HIF1A rs11549467 heterozygous genotype were detected. As a consequence, the effects of this SNP could not be analysed. 
Fig. 1 Patient flowchart on included patients. Fifty-six patients had to be excluded from association analyses because of individual genotyping call rates $<80 \%(N=6)$, relocation to another medical center during follow-up $(N=10)$, double patient $(N=1)$, a change to another treatment than sunitinib directly after enrolment $(N=1)$ or nonclear cell subtypes $(N=38)$. A total of 374 sunitinib-treated clear cell $\mathrm{mRCC}$ patients were available for analysis of toxicity in the present study. For efficacy analysis, 336 sunitinib-treated clear cell $\mathrm{mRCC}$ patients were available [12]

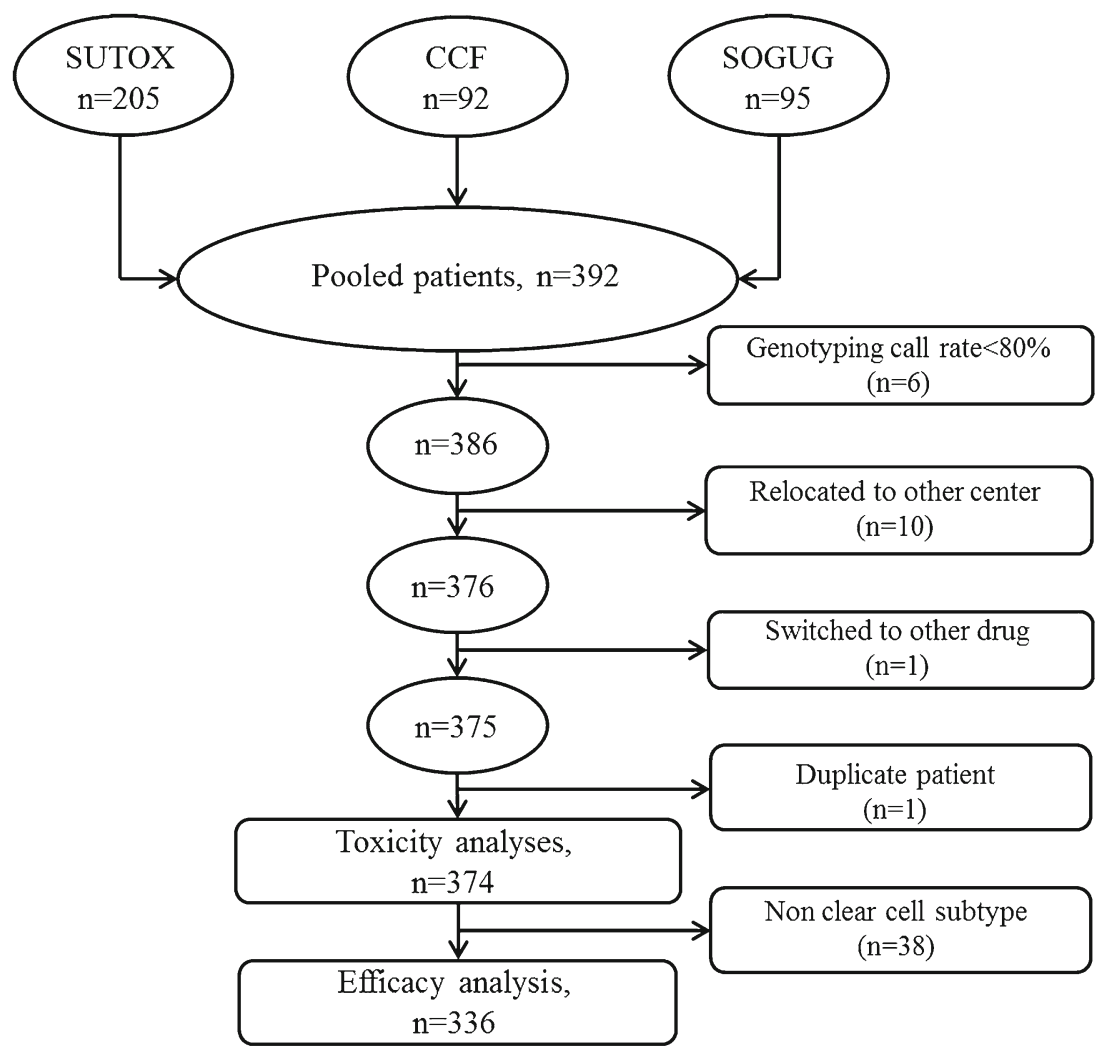

\section{Genetic association analysis}

No significant associations between SNPs and PFS, OS or objective response to sunitinib were observed in this study. Although not significant, A-allele carriers of $M E T$ rs11762213 had a better PFS compared to wild-type GG (HR $=0.63,95 \% \mathrm{CI}=0.38-1.05, P=0.076)$, adjusted for age, gender, Heng prognostic risk group, study group and CGT haplotype in $A B C B 1$ (Table 3).

In multivariate toxicity analysis, the T allele of $I L 8$ rs1126647 was associated with an increased risk of hypertension compared to wild-type AA $(\mathrm{OR}=1.69,95 \% \mathrm{CI}=1.07$ 2.67, $P=0.024$ ) after adjustment by age, gender and study group. Presence of the $I L 13$ rs 1800925 T allele was associated with an increased risk of leukopenia $(\mathrm{OR}=6.76,95 \% \mathrm{CI}=$ $1.35-33.9, P=0.020)$ and also with development of any toxicity $>$ grade $2(\mathrm{OR}=1.75,95 \% \mathrm{CI}=1.06-2.88, P=0.028)$ (Table 3).

\section{Discussion}

In the present study, we analysed eight candidate SNPs in seven genes for potential association with response and/or toxicity of sunitinib in a large cohort of $\mathrm{mRCC}$ patients. To our knowledge, we report for the first time that genetic polymorphisms in interleukin genes $I L 8$ and $I L 13$ are associated with the occurrence of clinically relevant adverse events from sunitinib. Patients carrying a T allele of IL 8 rs 1126647 had an increased risk of hypertension compared to wild-type AA $(\mathrm{OR}=1.69)$. T carriers of $I L 13 \mathrm{rs} 1800925 \mathrm{had}$ an increased risk of leukopenia $(\mathrm{OR}=6.76)$ and an increased risk of any toxicity $>$ grade $2(\mathrm{OR}=1.75)$.

Hypertension is a frequent toxicity caused by TKIs. The potential mechanism is suggested to be related to inhibition of VEGFR-2 and decrease of nitric oxide, resulting in vasoconstriction and elevated blood pressure [8, 24]. It has been recognized that IL8, possibly by upregulating VEGF levels through NFkappaB $[25,26]$, can play a role in stimulating VEGFR-2 transactivation. In our data, presence of the variant allele in $I L 8$ rs $1126647 \mathrm{~A}>\mathrm{T}$ is significantly associated with hypertension. $I L 8$ rs $1126647 \mathrm{~A}>\mathrm{T}$ is in linkage with $I L 8$ rs4073T $>\mathrm{A}\left(r^{2}=0.78\right)[16]$. It was shown that a haplotype of $I L 8$, including the variant allele of $\mathrm{rs} 4073 \mathrm{~T}>\mathrm{A}$ and rs $1126647 \mathrm{~A}>\mathrm{T}$, was associated with increased IL8 expression [27]. In contrast, Amaya et al. [28] have reported that the variant allele of rs 4073 was associated with a lower production of IL8. It remains to be elucidated whether particular SNPs in $I L 8$ have prognostic or even predictive significance in metastatic renal cell carcinoma.

The occurrence of hypertension is a well-known predictor for increased survival in metastatic renal cell carcinoma treated with a TKI [29]. In addition to an increased occurrence of hypertension, patients with the variant allele in IL8 
Table 2 Patient characteristics

\begin{tabular}{|c|c|c|}
\hline Characteristic & $\begin{array}{l}\text { Efficacy cohort } \\
(N=336)\end{array}$ & $\begin{array}{l}\text { Toxicity cohort } \\
(N=374)\end{array}$ \\
\hline \multicolumn{3}{|l|}{ Age } \\
\hline Median & 61 & 61 \\
\hline Percentiles (25th, 75th) & 55,69 & 54,68 \\
\hline \multicolumn{3}{|l|}{ BSA } \\
\hline Median & 1.98 & 1.96 \\
\hline Percentiles (25th, 75th) & $1.82,2.13$ & $1.82,2.12$ \\
\hline \multicolumn{3}{|l|}{ Race } \\
\hline White & $324(96 \%)$ & $358(96 \%)$ \\
\hline Asian & $3(0.89 \%)$ & $3(0.80 \%)$ \\
\hline Black & $5(1.5 \%)$ & $8(2.1 \%)$ \\
\hline Arabian & $3(0.89 \%)$ & $4(1.0 \%)$ \\
\hline Latin American & $1(0.30 \%)$ & $1(0.27 \%)$ \\
\hline \multicolumn{3}{|l|}{ Gender } \\
\hline Male & $229(68 \%)$ & $258(69 \%)$ \\
\hline Female & $107(32 \%)$ & $116(31 \%)$ \\
\hline \multicolumn{3}{|l|}{ Clinical response } \\
\hline $\mathrm{PR}+\mathrm{CR}$ & $143(43 \%)$ & $149(40 \%)$ \\
\hline SD & $130(39 \%)$ & $149(40 \%)$ \\
\hline $\mathrm{PD}$ & $43(13 \%)$ & $55(15 \%)$ \\
\hline Unknown & $20(6.0 \%)$ & $21(5.6 \%)$ \\
\hline \multicolumn{3}{|l|}{ Heng prognostic risk group ${ }^{a}$} \\
\hline Good (0 risk factor) & $64(19 \%)$ & $68(18 \%)$ \\
\hline Intermediate (1-2 risk factors) & $182(54 \%)$ & $197(53 \%)$ \\
\hline Poor (3-6 risk factors) & $90(27 \%)$ & $108(29 \%)$ \\
\hline \multicolumn{3}{|l|}{ Metastatic sites } \\
\hline 1 & $91(27 \%)$ & $105(28 \%)$ \\
\hline 2 & $137(41 \%)$ & $149(40 \%)$ \\
\hline$\geq 3$ & $104(31 \%)$ & $116(31 \%)$ \\
\hline \multicolumn{3}{|l|}{ Prior nephrectomy } \\
\hline No & $49(15 \%)$ & $63(17 \%)$ \\
\hline Yes & $283(85 \%)$ & $307(82 \%)$ \\
\hline \multicolumn{3}{|l|}{ Prior treatment } \\
\hline No & $254(76 \%)$ & $276(74 \%)$ \\
\hline Yes & $82(24 \%)$ & $98(26 \%)$ \\
\hline
\end{tabular}

$B S A$ body surface area, $C R$ complete response, $P R$ partial response, $S D$ stable disease, $P D$ progressive disease

${ }^{a}$ Patients are classified according to the six Heng risk criteria: poor WHO performance status $(\geq 2)$, low haemoglobin ( $<$ lower limit of normal), high calcium (>upper limit of normal) and time from initial diagnosis to treatment with sunitinib ( $<1$ year), neutrophil count (>upper limit of normal) and thrombocytes (>upper limit of normal)

rs $1126647 \mathrm{~A}>\mathrm{T}$ showed a trend towards improved PFS/OS $(22$ vs 14 months for median PFS and 40 vs 25 months for median OS), although the differences between groups did not reach statistical significance. One possible reason for the lack of statistical significance in the above association may be the $\sim 2$ fold larger $(n=544)$ sample size of the study from Rini et al. [29]. Xu et al. [16] described an inferior PFS of pazopanib for carriers of the variant allele of $I L 8$ rs1126647A $>$ T. In a follow-up study, Xu et al. [30] reported that the variant allele of $I L 8$ rs $1126647 \mathrm{~A}>\mathrm{T}$ was significantly associated with worse OS in $\mathrm{mRCC}$ patients treated with pazopanib or sunitinib, but could not confirm the initial association with PFS. Unfortunately, Xu et al. do not report data on associations between IL8 rs1126647 and hypertension. In addition, many factors can have an impact on OS, including baseline conditions and previous and posterior treatments. Therefore, it is not possible to directly compare the association of IL8 rs1126647 and hypertension/survival between the two datasets and further study in an independent cohort is required.

We observed an increased risk of leukopenia in carriers of the variant allele of IL13 rs $1800925 \mathrm{C}>\mathrm{T}$. Leukopenia is a common haematologic adverse event in sunitinib treatment of which the mechanism remains uncertain. It was reported that VEGF and its receptors (VEGFR) are essential for development of aberrant haematopoiesis, including leukopenia [31]. Shen et al. [32] have reported that VEGFR-2 can be upregulated by IL13. The T allele of IL13 rs1800925 has been found to be associated with increased IL13 protein function [33].

Little is known about the effects of SNPs in IL8 and IL13, but it is likely that these SNPs will either increase or decrease the protein expression of IL8 and IL13 proteins [24-26, 29, 31-34]. It also remains unclear whether the function of these interleukins will affect TKI treatment outcome and if and how these interleukin proteins would influence the $\operatorname{VEGF}(\mathrm{R})$ pathway directly or indirectly [25-28, 30-36]. Xu et al. [30] speculate that patients with the IL8 variants having a high IL8 expression may have more aggressive tumours, and therefore a reduced survival. However, it is difficult to hypothesize because we noticed conflicting results: Hacking et al. [27] reported increased expression for $I L 8$ variants, while a more recent paper of Amaya et al. [28] reported the opposite effect on IL8 expression. If variant alleles in IL8 and IL13 SNPs alter protein expression and have an effect on VEGF-R2, a stronger inhibition of VEGF-R2 in the concomitant presence of sunitinib would explain our results on a higher risk for any toxicity, including hypertension and leukopenia.

HIF 1A protein regulates the transcription of a large number of genes that respond to hypoxia, among which is angiogenesis. The A-allele frequency of $H I F 1 \mathrm{~A}$ rs 11549467 in our cohort was $0.45 \%$, which is lower than that $(A=3.0 \%)$ reported by $\mathrm{Xu}$ et al. [16], but corresponds with the result $(A=0.6 \%)$ from Beuselinck et al. [10]. The difference in A-allele frequency is potentially caused by the subject selection. Of note, the subjects recruited here and in the study of Beuselinck typically have Western European ancestry, whereas the patients in Xu's study are mostly from Eastern Europe [10, 16]. 
Table 3 Univariate and multivariate analyses for SNPs associated with sunitinib treatment outcome

\begin{tabular}{|c|c|c|c|c|c|c|c|}
\hline \multirow[t]{2}{*}{ Treatment outcome } & \multirow[t]{2}{*}{ Number of patients } & \multicolumn{3}{|c|}{ Univariate analyses } & \multicolumn{3}{|c|}{ Multivariate analyses } \\
\hline & & HR or OR & $95 \% \mathrm{CI}$ & $P$ value & HR or OR & $95 \%$ CI & $P$ value \\
\hline \multicolumn{8}{|l|}{ PFS } \\
\hline MET rs $11762213 \mathrm{G}>\mathrm{A}$ & & 0.58 & $0.36-0.96$ & 0.032 & 0.63 & $0.38-1.05$ & $0.076^{\mathrm{a}}$ \\
\hline GG versus & 302 & & & & & & \\
\hline $\mathrm{AG}+\mathrm{AA}$ & 33 & & & & & & \\
\hline \multicolumn{8}{|l|}{ Hypertension } \\
\hline$I L 8 \mathrm{rs} 1126647 \mathrm{~A}>\mathrm{T}$ & & 1.70 & $1.08-2.68$ & 0.022 & 1.69 & $1.07-2.67$ & $0.024^{\mathrm{b}}$ \\
\hline AA versus & 128 & & & & & & \\
\hline AT versus & 174 & & & & & & \\
\hline TT & 61 & & & & & & \\
\hline \multicolumn{8}{|l|}{ Thrombocytopenia } \\
\hline IL13 rs20541 C>T & & 1.97 & $0.90-4.35$ & 0.092 & 1.87 & $0.82-4.23$ & $0.136^{\mathrm{b}}$ \\
\hline $\mathrm{CC}$ versus & 235 & & & & & & \\
\hline $\mathrm{CT}+\mathrm{TT}$ & 117 & & & & & & \\
\hline \multicolumn{8}{|l|}{ Leukopenia } \\
\hline IL13 rs $1800925 \mathrm{C}>\mathrm{T}$ & & 6.13 & $1.25-30.0$ & 0.025 & 6.76 & $1.35-33.9$ & $0.020^{\mathrm{b}}$ \\
\hline $\mathrm{CC}$ versus & 232 & & & & & & \\
\hline $\mathrm{CT}+\mathrm{TT}$ & 137 & & & & & & \\
\hline \multicolumn{8}{|l|}{ Any toxicity $>$ grade 2} \\
\hline IL13 rs1800925 C>T & & 1.91 & $1.15-3.15$ & 0.012 & 1.75 & $1.06-2.88$ & $0.028^{\mathrm{b}}$ \\
\hline $\mathrm{CC}$ versus & 234 & & & & & & \\
\hline $\mathrm{CT}+\mathrm{TT}$ & 137 & & & & & & \\
\hline
\end{tabular}

$H R$ hazard ratio, $O R$ odds ratio, $C I$ confidence interval, $P F S$ progression-free survival

${ }^{a}$ Adjusted by age, gender, Heng prognostic risk group, study center and $A B C B 1$ haplotype

${ }^{\mathrm{b}}$ Adjusted by age, gender and study center

This study was conducted in a relatively large cohort, which decreases the chance for false-positive findings. In addition to $\mathrm{Xu}$ et al. [30], we have tested on toxicity as well as efficacy endpoints, which is essential for clinical interpretation. SNPs could influence the drug exposure to the TKI and consequently have an effect on both adverse events, PFS and OS. Because this study only presents explorative findings without external validation, and our results are based on mainly Caucasian subjects, extrapolation to the entire $\mathrm{mRCC}$ population is difficult.

To capture adverse events that occur later on in treatment, all toxicity outcomes were recorded and evaluated up to four cycles of sunitinib treatment. In our cohort, hypertension and fatigue have a large contribution in the endpoint any toxicity $>$ grade 2. Because it is difficult to evaluate fatigue objectively, we did not test fatigue as separate toxicity endpoint. Since our study represents data collected from 2004 to 2010, it is likely that clinical practice (i.e. toxicity management) has evolved in the course of time. In earlier years with limited experience on sunitinib treatment, dose reductions were applied in the case of grade 3 or 4 toxicities. Nowadays, physicians anticipate on the development of severe adverse events by already reducing the dose on the occurrence of grade 2 toxicity. However, we did not observe a difference in dose reductions between earlier years and later years (data not shown). Further, our dataset lacks sufficiently detailed information on the reasons and time points of dose reductions.

Our SNP selection was based on reported associations with toxicity and efficacy outcomes on treatment and the risk of developing RCC. SNPs are often categorized as being either predictive or prognostic biomarkers. However, this distinction may not have to be as rigorous as we currently assume. In fact, prediction and prognosis may be strongly correlated. Antitumour treatment can have a different effect in patients with a more aggressive tumour type that is possibly caused by an underlying SNP. For example, high IL8 protein levels in RCC are considered to have a poor prognosis [35]. However, elevated IL8 levels investigated in preclinical models resulted in resistance to sunitinib, which would be considered predictive [36]. Functional studies on immunological and angiogenic factors and a genome-wide approach can help us in understanding the mechanisms on the predictive or prognostic character of the SNPs. 
In conclusion, this study suggests a relationship between interleukin genes IL8 and ILI3 and the development of sunitinib-induced adverse events. Further validation in an independent cohort is warranted to confirm our findings. In addition, we consider functional studies on IL8 and IL13, with respect to regulation of $\operatorname{VEGF}(\mathrm{R})$ genes and $\mathrm{SVEGF}(\mathrm{R})$ plasma levels, to be crucial for our understanding of the mechanisms involved in sunitinib exposure and occurrence of adverse events.

Acknowledgments We thank Dr. Tahar van der Straaten and Renée Baak-Pablo for their assistance with data management and genotyping.

Contributions of authors Study concept and design: Rini, GarciaDonas, Guchelaar

Acquisition of data: Diekstra, Swen, Boven, Castellano, Gelderblom, Mathijssen, Rodriguez-Antona, Garcia-Donas, Rini, Guchelaar

Analysis and interpretation of data: Diekstra, Liu, Swen, Rini, GarciaDonas, Rodriguez-Antona, Gelderblom, Guchelaar

Drafting of the manuscript: Diekstra, Liu, Swen, Boven, Castellano, Gelder- blom, Mathijssen, Rodriguez-Antona, Garcia-Donas, Rini, Guchelaar

Critical revision of the manuscript: Diekstra, Swen, Boven, Castellano, Gelderblom, Mathijssen, Rodríguez- Antona, García-Donas, Rini, Guchelaar

Statistical analysis: Diekstra, Liu, Swen, Rini, Garcia-Donas, Rodríguez- Antona, Gelderblom, Guchelaar.

Administrative, technical or material support: Diekstra, Swen, Boven, Castellano, Gelderblom, Mathijssen, Rodríguez-Antona, García-Donas, Rini, Guchelaar

Supervision: Guchelaar

Funding Pfizer supports this research. The European Union's Seventh Framework Programme (FP7/2007-2013) supports Meta Diekstra under grant agreement no. 259939. Xiaoyan Liu is supported by the Chinese Scholarship Council under grant agreement no. [2014]3026.

Conflict of interest Dr. Brian Rini and Dr. Garcia-Donas report consulting and research funding from Pfizer. The other authors declared no conflicts of interest.

Open Access This article is distributed under the terms of the Creative Commons Attribution 4.0 International License (http:// creativecommons.org/licenses/by/4.0/), which permits unrestricted use, distribution, and reproduction in any medium, provided you give appropriate credit to the original author(s) and the source, provide a link to the Creative Commons license, and indicate if changes were made.

\section{References}

1. Motzer RJ, Rini BI, Bukowski RM et al (2006) Sunitinib in patients with metastatic renal cell carcinoma. JAMA 295:2516-2524

2. Motzer RJ, Hutson TE, Cella D et al (2013) Pazopanib versus sunitinib in metastatic renal-cell carcinoma. N Engl J Med 369: $722-731$

3. Shibata SI, Chung V, Synold TW et al (2013) Phase I study of pazopanib in patients with advanced solid tumors and hepatic dysfunction: a National Cancer Institute Organ Dysfunction Working Group study. Clin Cancer Res 19:3631-3639

4. Houk BE, Bello CL, Kang D, Amantea M (2009) A population pharmacokinetic meta-analysis of sunitinib malate (SU11248) and its primary metabolite (SU12662) in healthy volunteers and oncology patients. Clin Cancer Res 15:2497-2506

5. van Erp NP, Eechoute K, van der Veldt AA et al (2009) Pharmacogenetic pathway analysis for determination of sunitinibinduced toxicity. J Clin Oncol 27:4406-4412

6. van der Veldt AA, Eechoute K, Gelderblom H et al (2011) Genetic polymorphisms associated with a prolonged progression-free survival in patients with metastatic renal cell cancer treated with sunitinib. Clin Cancer Res 17:620-629

7. Garcia-Donas J, Esteban E, Leandro-García LJ et al (2011) Single nucleotide polymorphism associations with response and toxic effects in patients with advanced renal-cell carcinoma treated with first-line sunitinib: a multicentre, observational, prospective study. Lancet Oncol 12:1143-1150

8. Eechoute K, van der Veldt AA, Oosting S et al (2012) Polymorphisms in endothelial nitric oxide synthase (eNOS) and vascular endothelial growth factor (VEGF) predict sunitinibinduced hypertension. Clin Pharmacol Ther 92:503-510

9. Kim JJ, Vaziri SA, Rini BI et al (2010) Association of VEGF and VEGFR2 single nucleotide polymorphisms with hypertension and clinical outcome in metastatic clear cell renal cell carcinoma patients treated with sunitinib. Cancer 118:1946-1954

10. Beuselinck B, Karadimou A, Lambrechts D et al (2013) Singlenucleotide polymorphisms associated with outcome in metastatic renal cell carcinoma treated with sunitinib. Br J Cancer 108:887900

11. Beuselinck B, Karadimou A, Lambrechts D et al (2014) VEGFR1 single nucleotide polymorphisms associated with outcome in patients with metastatic renal cell carcinoma treated with sunitiniba multicentric retrospective analysis. Acta Oncol 53:103-112

12. Diekstra MH, Swen JJ, Boven E et al (2015) CYP3A5 and ABCB1 polymorphisms as predictors for sunitinib outcome in metastatic renal cell carcinoma. Eur Urol 68:621-629

13. Elens L, Bouamar R, Hesselink DA et al (2011) A new functional CYP3A4 intron 6 polymorphism significantly affects tacrolimus pharmacokinetics in kidney transplant recipients. Clin Chem 57: 1574-1583

14. Elens L, van Gelder T, Hesselink DA et al (2013) CYP3A4*22: promising newly identified CYP3A4 variant allele for personalizing pharmacotherapy. Pharmacogenomics 14:47-62

15. Diekstra MH, Klümpen HJ, Lolkema MP et al (2014) Association analysis of genetic polymorphisms in genes related to sunitinib pharmacokinetics, specifically clearance of sunitinib and SU12662. Clin Pharmacol Ther 96:81-89

16. Xu CF, Bing NX, Ball HA et al (2011) Pazopanib efficacy in renal cell carcinoma: evidence for predictive genetic markers in angiogenesis-related and exposure-related genes. J Clin Oncol 29: $2557-2564$

17. De Jonge H, Metalidis C, Naesens $M$ et al (2011) The P450 oxidoreductase *28 SNP is associated with low initial tacrolimus exposure and increased dose requirements in CYP3A5-expressing renal recipients. Pharmacogenomics 12:1281-1291

18. Oneda B, Crettol S, Jaquenoud Sirot E et al (2009) The P450 oxidoreductase genotype is associated with CYP3A activity in vivo as measured by the midazolam phenotyping test. Pharmacogenet Genomics 19:877-883

19. Chu H, Wang M, Yan F et al (2012) Polymorphisms in the IL13 and IL-4R genes are associated with the development of renal cell carcinoma. Ann Oncol 23:2114-2121

20. Schutz FA, Pomerantz MM, Gray KP et al (2013) Single nucleotide polymorphisms and risk of recurrence of renal-cell carcinoma: a cohort study. Lancet Oncol 14:81-87 
21. Kumar R, Crouthamel MC, Rominger DH et al (2009) Myelosuppression and kinase selectivity of multikinase angiogenesis inhibitors. Br J Cancer 101:1717-1723

22. Heng D, Xie W, Regan M et al (2009) Prognostic factors for overall survival in patients with metastatic renal cell carcinoma treated with vascular endothelial growth factor-targeted agents: results from a large, multicenter study. J Clin Oncol 27:5794-5799

23. Sherry ST, Ward MH, Kholodov M et al (2001) National Center for Biotechnology Information (NCBI) SNP database: the NCBI database of genetic variation. Nucleic Acids Res 29:308-311. Available from URL: http://www.ncbi.nlm.nih.gov/snp/

24. Lankhorst S, Kappers M, van Esch J et al (2014) Hypertension during vascular endothelial growth factor inhibition: focus on nitric oxide, endothelin-1, and oxidative stress. Antioxid Redox Signal 20:135-145

25. Petreaca ML, Yao M, Liu Y et al (2007) Transactivation of vascular endothelial growth factor receptor-2 by interleukin-8 (IL8/CXCL8) is required for IL8/CXCL8-induced endothelial permeability. Mol Biol Cell 18:5014-5023

26. Martin D, Galisteo R, Gutkind JS (2009) CXCL8/IL8 stimulates vascular endothelial growth factor (VEGF) expression and the autocrine activation of VEGFR2 in endothelial cells by activating NFkappaB through the CBM (Carma3/Bcl10/Malt1) Complex. J Biol Chem 284:6038-6042

27. Hacking D, Knight JC, Rockett K et al (2004) Increased in vivo transcription of an IL8 haplotype associated with respiratory syncytial virus disease susceptibility. Genes Immun 5:274-282

28. Amaya MP, Criado L, Blanco B et al (2013) Polymorphisms of proinflammatory cytokine genes and the risk for acute suppurative or chronic nonsuppurative apical periodontitis in a Colombian population. Int Endod J 46:71-78

29. Rini BI, Cohen DP, Lu DR et al (2011) Hypertension as a biomarker of efficacy in patients with metastatic renal cell carcinoma treated with sunitinib. J Natl Cancer Inst 103:763-773

30. Xu CF, Johnson T, Garcia-Donas J et al (2015) IL8 polymorphisms and overall survival in pazopanib- or sunitinib-treated patients with renal cell carcinoma. Br J Cancer 112:1190-1198

31. Huang Y, Chen X, Dikov MM et al (2007) Distinct of VEGFR-1 and VEGFR-2 in the aberrant hematopoiesis associated with elevated levels of VEGF. Blood 110:624-631

32. Shen R, Ye Y, Chen L et al (2008) Precancerous stem cells can serve as tumor vasculogenic progenitors. PLoS One 3, e1652

33. van der Pouw Kraan TC, van Veen A, Boeije LC et al (1999) An IL13 promoter polymorphism associated with increased risk of allergic asthma. Genes Immun 1:61-65

34. Tran HT, Liu Y, Zurita AJ et al (2012) Prognostic or predictive plasma cytokines and angiogenic factors for patients treated with pazopanib for metastatic renal-cell cancer: a retrospective analysis of phase 2 and phase 3 trials. Lancet Oncol 13:827-837

35. Harmon CS, DePrimo SE, Figlin RA et al (2014) Circulating proteins as potential biomarkers of sunitinib and interferon- $\alpha$ efficacy in treatment-naïve patients with metastatic renal cell carcinoma. Cancer Chemother Pharmacol 73:151-161

36. Huang D, Ding $Y$, Zhou $M$ et al (2010) Interleukin-8 mediates resistance to antiangiogenic agent sunitinib in renal cell carcinoma. Cancer Res 70:1063-1071 